\title{
Risk-return-volume relationship in an emerging stock market
}

\author{
Ferhan SALMAN*
}

Affiliation and Correspondence:

\author{
Research Department \\ The Central Bank of the Republic of Turkey \\ Ýstiklal Cd. No:10 \\ 06100 Ulus-Ankara \\ TURKEY
}

All the views expressed in this paper belong to the authors and do not represent the views of the Central Bank of the Republic of Turkey

\section{E-mail: Ferhan.Salman@tcmb.gov.tr \\ Fax: (+90 312) 3242303}

\begin{abstract}
This paper aims to provide empirical evidence for the risk-return-volume relationship in the Ýstanbul Stock Exchange (ISE) for the period of January 2, 1992 - May 29, 1998. The Generalised Autoregressive Conditional Heteroscedasticity-in-Mean (GARCH-M) specification reveals that daily return volatility is time-varying and highly persistent. In addition, return is positively associated with risk, i.e. the estimate of the conditional standard deviation. Contemporaneous changes in volume have a positive effect on returns. The previous day's change in volume affects positively conditional volatility of returns.
\end{abstract}

Key words: Risk-return relationship, volume, GARCH models JEL Classification: C22, G11

\footnotetext{
* Thanks to Hakan Berument, Ahmet Kýpýcý and Ercan Balaban for their valuable

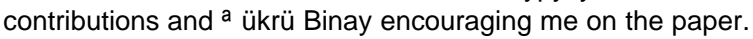




\section{INTRODUCTION}

Risk is one of the main factors that determine return. In countries with high inflation, return should be higher in order to compensate the risk evolved in the system and encourage capital inflow to the country. Whereas, return constitutes all the information implicitly through its interaction with volume, interbank rate (Muradoðlu, Berument and Metin, 1998, and Balaban and Kunter, 1997) and other instruments in the financial markets.

The importance of the Ýstanbul Stock Exchange (ISE) lies in its fast growth since its establishment in 1986. In a ten year time it increased its price performance on US-dollar basis three-fold. The ISE is ranked within the top ten developing markets of the world and ranked eight in Europe, also in terms of average daily turnover it has been way in front of markets such as Oslo, Brussels, Copenhagen, Madrid and competes with Amsterdam, Milan and Stockholm Stock Exchanges. Turkey has recently one of the most liberalised foreign exchange regimes; foreigners own around 3 billion US dollars worth of shares, which constitute almost half of the shares in the ISE (ISE, 1998; Yýldýrým, 1996). Nevertheless, average daily trading volume reaches up to 474 million US dollars, bonds and bills markets up to 1.76 billion US dollars and Repurchase Agreement and Reverse Repurchase Agreement (Repo/Reverse - Repo) market up to 1.5 billion US dollars (ISE, 1998).

The main purpose of the paper is to search for the relationship between risk, return and volume in the ISE by 
applying an Autoregressive Conditional Heteroskedasticity $(\mathrm{ARCH})$ specification. The main reason to use $\mathrm{ARCH}$ lies in the fact that a conditional stochastic process generates the return data with a changing variance. Therefore, it is naturally expected that $\mathrm{ARCH}$ is the right tool to approach to the problem since it takes the changing variances into consideration. Risk Return relationship will be examined throughout the paper and the information flow in the ISE will be tested. It is expected that in the equity market of the ISE return is positively related to both risk and volume. For estimation and testing the validity of the hypothesis a more parsimonious specification of $\mathrm{ARCH}$ which is Generalised ARCH in Mean (GARCH - M) specification will be used (Lamourex and Lastrapes, 1990).

Earlier studies on the price - volume relationship examine the relationship within a several methodologies including the cointegration analysis. Positive correlation between the two variables is observed for most of the studies (Karpoff, 1987). One of the particular studies by using cointegration analysis made on the ISE which took account of 166 weeks for the January 8, 1988 - March 29, 1991 period on 29 individual stocks supports the hypothesis of the positive relationship (Bapçý, Özyýldýrým and Aydoðan, 1996). In this context, this paper is the first attempt that provides the reader with a larger range of time period and employ a different methodology (ARCH specification) to test the hypothesis and take the relationship arising from an information flow in the market proxied by volume in contribution to the already existing risk in the market. Volume is taken as a proxy for the 
information flow as suggested by Morgan (1976) since volume is associated with risk.

Section II of this study describes the data and the econometric method employed to assess the risk, volume and return relationship, section III provides empirical evidence, section IV gives the concluding remarks.

\section{THE DATA AND MODEL}

Daily data for the period of January 2, 1992 - May 29, 1998 employed is as follows: ISE composite index (ISE-CI) is a value weighted index calculated according to closing prices of common shares and published by the ISE is used to calculate return, volume is taken as the total amount of operations done during the day in terms Turkish Lira units. The original data source of the variables is the ISE however obtained from the database of the Central Bank of the Republic of Turkey. The sample size is taken to be 1586 and the significance level is taken to be 5 percent.

Risk is taken to be one of the determinants of the return in the financial markets. It is assumed that information set determines return in financial markets, so that, because volume is affected by both exogenous and endogenous shocks felt in the economy, it is taken as a proxy for information flow in the market and introduced as an explanatory variable in the equations. Since, information at time (t-1) is important, where volume is assumed to have a direct impact on risk, it is introduced in the variance equation with one period lag. 
Assume that daily stock return $R_{t}$ and daily trading volume $V_{t}$ are expressed as

$$
R_{t}=\log \left(I S E-C I_{t} / I S E-C I_{t-1}\right) \text { and } V_{t}=\log \left(\text { volume }_{t} / \text { volume }_{t-1}\right)
$$

The GARCH introduced by Bollerslev (1986) and ARCH in Mean (ARCH-M) introduced by Engel, Lilien and Robins (1987) provide the forecast variance to vary over time and lag values to be included in the variance equation. The main reason to choose $\mathrm{GARCH}$ specification instead of $\mathrm{ARCH}$ specification basically lies on the fact that higher order $\mathrm{ARCH}$ representation which is $\mathrm{GARCH}$ is parsimonious and easier to identify and estimate (Enders, 1995). The modified version of GARCH - M $(1,1)$ is specified by the introduction of volume into our equation and called Augmented GARCH - M $(1,1)$ estimation. Also, empirical evidence suggests (Lamourex and Lastrapes, 1990) that for the risk - return relationship GARCH M provides reasonable starting point.

Risk and volume are taken to be explanatory variables in the system. Empirical evidence points that there is a significant day of the week effect in the ISE (Balaban, 1995). Hence, the specification includes the dummies reflecting the daily pattern. Constant term is not added into the equation in order to avoid multicollinearity trap.

$R_{\mathrm{t}-\mathrm{i}}$ is the $\mathrm{i}^{\text {th }}$ lag length of daily stock return, $D_{j}^{\prime} \mathrm{s}$ are the dummy variables representing the days of the week, $V_{t}$ represents volume, which is also expressed in log-first difference form, in the stock market, $h_{t}$ is the estimated square- 
root of variance taken to be a proxy for risk $^{1}$ as suggested by ARCH-M specification and $e_{t}$ is the stochastic process and assumed to be distributed normally conditional on the information set $\Psi_{t-1}$ given to the individual at time $t-1$

$$
\begin{aligned}
\mathrm{R}_{\mathrm{t}} & =\sum_{J=1}^{5} \alpha_{j} D_{j}+\sum_{\mathrm{i}=1}^{\mathrm{N}} a_{i} R_{t-i}+\varphi h_{t}+\mu V_{t}+e_{t} \\
h_{t}^{2} & =\beta_{0}+\sum_{i=1}^{q} \beta_{i} e^{2}{ }_{t-i}+\sum_{i=1}^{p} \omega_{i} h_{t-i}^{2}+\mu V_{t-1} \\
\mathrm{e}_{\mathrm{t}} & \mid \Psi_{t-1} \sim \mathrm{N}\left(0, \mathrm{~h}_{\mathrm{t}}\right)
\end{aligned}
$$

Each $\beta_{i}, \omega_{i}>0$ and sum of $\beta_{i}+\omega_{i} \leq 1$ for $\mathrm{i} \geq 1$ should be satisfied for the model not to be explosive and to guarantee positive variances. However, with the inclusion of one period lag value of volume in the equation this condition may fail, despite it will be tested empirically.

\section{ESTIMATION AND RESULTS}

Risk - return relationship is initially examined by excluding volume which is represented by GARCH - M $(1,1)$ where the results are presented on column I of the Table. ${ }^{2}$ Bollerslev and Woolridge standard errors are used to test the

\footnotetext{
${ }^{1}$ The main reason to choose the square root of variance $\left(h_{t}\right)$ rather than variance $\left(h_{t}^{2}\right)$ lies on the calculations that the log-likelihood function is maximized by using $h_{t}$ and $h_{t}$ is significant at the 5 percent level where $h_{t}^{2}$ turns out to be significant at the 10 percent level in the final model.

${ }^{2}$ Log first differences of Volume and Return are stationary, i.e. integrated of order 1 , according to the Augmented Dickey-Fuller test; results are ommited to save space but available upon request.
} 
hypotheses. The lagged values of return are chosen to be 3 , which is chosen according to the Akaike and Schwarz Criterion. Risk turns out to be positively related with return but turns out to be insignificant, which is a possible signal of a misspecification. Because of " $t+2$ " settlement, the second lag of the return $\left(R_{t-2}\right)$ has a negative impact on return.

Day of the week effects turn out to be jointly significant. The Monday and Tuesday dummies turn out to be negatively related with return and the rest of the days are positively related to return. This arises from the " $t+2 "$ settlement in the ISE. The payments of the shares are made two business days after the transaction is made. So the payment of the transactions made on Thursday and Friday are made on Monday and Tuesday. This has two implications, one is the investor gains two extra days for the payment so that purchases on Thursday and Friday turn out to be higher than the other days, the other is, on Monday and Tuesday the already accrued profit is realised where sales are mostly made on these two days.

Also, the ARCH - LM statistics indicates no autocorrelation in the specification. The explanatory variables in the variance (risk) equation are all positively related to risk and the coefficients satisfy the $\beta_{1}, \omega_{1}>0$ and sum of $\beta_{1}+\omega_{1}<1$ condition. As a conclusion, the process is not explosive and conditional variance is positive for the sample.

By including the one period lag value of volume $\left(\mathrm{V}_{\mathrm{t}-1}\right)$ as an explanatory variable in the risk equation, the specification of GARCH - M is as given by (2) where $\mu$ is set equal to zero in the mean equation, which is called the Augmented GARCH $M(1)$, is obtained. The model is estimated and presented on 
column II of the table. It is interesting to see that $\mathrm{V}_{\mathrm{t}-1}$ is significant. It is also important to note that the sign of the coefficients of the day of the week effect dummies change sign. The reason could be that the volume turns out to be more important than the day of the week effects, however, still the dummies appear to be jointly significant. Also, risk turns out to be significant and has a positive impact on return. This arises from the significance of the information content in the lag value of volume which affects volatility in the market. The increasing volatility in the market increases risk and eventually return.

It is observable that the day dummies for Monday and Tuesday have a stronger negative effect than the other three day dummies, which is also parallel to our results on column I. Still the system is not explosive since the coefficients satisfy the $\beta_{1}, \omega_{1}>0$ and sum of $\beta_{1}+\omega_{1}<1$ condition in the risk equation. $^{3}$

By including the contemporaneous value of volume in the mean equation, the specification as shown by (2) and (3) is obtained. Results are presented on column III. Still the dummies are significant. $V_{t}$ turns out to be positively related to return where the daily information also affects return and still there is a positive interaction between return and risk. An interesting point to note is that the second lag of return alternate in sign. The possible reason is that the information content of the $R_{t-2}$ is already captured by volume. System is still not explosive.

\footnotetext{
3 Also, the results of the normality tests of the standardised residuals point out that residuals are not significantly different from normal distribution.
} 
It is evident that volume has both a direct and indirect effect on return. The first is the direct contemporaneous effect through the return equation, which is significant and positive. The indirect effect is also positive and significant, through information content at time $(\mathrm{t}-1)$, in the risk equation. These point out that the information flow in the market determines the risk and return in the market. However, risk has an individual impact on return. This should be noted as imperfect information in the market. So that the investors are making their choices directed by the imperfect information created by the economy. However, there still remains the day of the week effects where the daily pattern is also being followed by the stock market. As a conclusion, we may say that the new information arrival to the market, rather than uncertainty determines risk. This suggests that return is affected by the information arrival beside the market inherent stock market risk. However, information also affects return through variance equation. That means increase in volume is also felt in the volatility of the market and constitutes one of the factors of risk. Hence, risk associated with volume determine return in the market.

\section{CONCLUSION}

The paper tested the validity of risk-return and information-return relationship by using a GARCH-M representation of the estimation process. Volume is taken as a proxy for the information arrival to the market and is introduced both in the return and variance equations. It is found that there is a positive risk-return relationship when volume is incorporated to both return and variance equation the positive interaction between the volume and risk and return persists 
which supports the empirical foundations of the earlier work on emerging markets. In GARCH-M representation, the volume term did not vanish in both return and risk equations. Therefore, risk and return are both integrated to the information provided to the market. 
REFERENCES

Balaban, E. (1995) Day of the week effects: new evidence from an emerging stock market, Applied Economic Letters, 2, 139-43.

Balaban, E. and Kunter, K. (1997) A note on the efficiency of financial markets in a developing country, Applied Economic Letters, 4, 109-12.

Bapçý, E., Özyýldýrým, S. and Aydoðan, K. (1996) A note on price-volume dynamics in an emerging stock market, Journal of Banking and Finance, 20, 389-400.

Berument, H. and Güner, N., (1997), Inflation, inflation risk and interest rates: a case study for Turkey, Metu Studies in Development, 24, 319-27.

Bollerslev, T. and Woolridge, J. M. (1992) Quasi maximum likelihood estimation and inference in dynamic models with time varying covariances, Econometric Reviews, 11, 143-72.

Bollerslev, T. (1986) Generalised autoregressive conditional heteroscedasticity, Journal of Econometrics, 31, 307-27.

Breusch, T.J. and Godfrey, L. G. (1986) Data transformation tests, Economic Journal, 96, Supplement, 47-58.

Enders, W. (1995) Applied Econometric Time Series, John Wiley and Sons, Canada, 141-61.

Engle, R. F., Lilien, D. M. and Robins, R. P. (1987) Estimating time-varying risk premia in the term structure: the $\mathrm{ARCH}$ M model, Econometrica, 55, 391-407.

Ýstanbul Stock Exchange (1998) Major developments since the inception of the ISE, available at http://www.ise.org/about/majordev.htm 
Karpoff, J. M. (1987) The relation between price changes and trading volume: a survey, Journal of Financial and Quantitative Analysis, 22, 109-26.

Lamoureux, C. G., Lastrapes, W. D., (1990) Heteroskedasticity in stock return data: volume versus garch effects, Journal of Finance, 45, 221-9.

Morgan, I. G. (1976) Stock prices and heteroskedasticity, Journal of Business, 49, 496-508.

Muradoðlu, G., Berument, H. and Metin, K. (1998) An empirical investigation of stock returns and determinants of risk in an emerging market: Istanbul Stock Exchange, Computations in Economics, Finance and Engineering:Economic Systems (CEFES'98) Preprints, IFAC:Society for Computational Economics Meeting'98, Cambridge, UK.

Yýldýrým, A. (1996) Fortunes made fortunes lost: The saga of the Ýstanbul Stock Exchange, Intermedia, Ýstanbul, 1-8. 
Table 1. Empirical Results of the Risk-Return-Volume Relationship

\begin{tabular}{|c|c|c|c|}
\hline & $\mathbf{I}$ & II & III \\
\hline & $\begin{array}{r}\text { GARCH-M } \\
(1,1) \\
\end{array}$ & $\begin{array}{r}\text { Augmented } \\
{\text { GARCH-M }(1,1)^{(1)}}^{-1}\end{array}$ & $\begin{array}{r}\text { Augmented } \\
\text { GARCH-M }(\mathbf{1}, \mathbf{1})^{(2)} \\
\end{array}$ \\
\hline \multicolumn{4}{|c|}{ Mean Equation } \\
\hline \multirow[t]{2}{*}{$R_{t-1}$} & ${ }^{\mathrm{a}} 0.117691$ * & 0.147667 * & 0.065559 ** \\
\hline & ${ }^{\mathrm{b}} 0.029150$ & 0.029138 & 0.027533 \\
\hline \multirow[t]{2}{*}{$R_{t-2}$} & -0.002272 & -0.018663 & 0.083225 * \\
\hline & 0.028911 & 0.029418 & 0.028441 \\
\hline \multirow[t]{2}{*}{$\mathrm{R}_{\mathrm{t}-3}$} & $0.067567 *$ & 0.062501 ** & 0.058978 ** \\
\hline & 0.026394 & 0.026374 & 0.024627 \\
\hline \multirow[t]{2}{*}{$V_{t}$} & 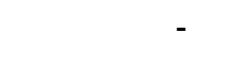 & . & 0.030099 * \\
\hline & & & 0.002331 ** \\
\hline$h_{t}$ & $\begin{array}{l}0.039382 \\
0.099393\end{array}$ & $\begin{array}{l}0.200881 \\
0.099686\end{array}$ & $\begin{array}{l}0.2365699^{\star *} \\
0.097820\end{array}$ \\
\hline \multirow[t]{2}{*}{$D_{m}$} & -0.000931 & -0.003237 * & -0.002085 *** \\
\hline & 0.001194 & 0.001209 & 0.001104 \\
\hline \multirow[t]{2}{*}{$D_{t}$} & -0.000146 & -0.002224 ** & -0.003007 * \\
\hline & 0.001153 & 0.001158 & 0.001028 \\
\hline \multirow[t]{2}{*}{$D_{w}$} & 0.001406 & -0.001006 & -0.001643 \\
\hline & 0.001164 & 0.001202 & 0.001099 \\
\hline \multirow{2}{*}{$D_{h}$} & 0.001508 & -0.000420 & -0.000884 \\
\hline & 0.001169 & 0.001189 & 0.001074 \\
\hline \multirow[t]{2}{*}{$D_{f}$} & 0.000648 & -0.001683 & -0.000870 \\
\hline & 0.001137 & 0.001161 & 0.001005 \\
\hline \multicolumn{4}{|c|}{ Variance Equation } \\
\hline \multirow[t]{2}{*}{$\beta_{0}$} & 0.000006 & 0.000008 * & 0.000003 * \\
\hline & 0.000002 & 0.000002 & 0.000001 \\
\hline \multirow[t]{2}{*}{$e_{t-1}^{2}$} & 0.109506 * & 0.120973 * & 0.088558 * \\
\hline & 0.022013 & 0.022673 & 0.016759 \\
\hline \multirow[t]{2}{*}{$h_{t-1}^{2}$} & 0.850118 * & 0.834337 * & 0.894224 * \\
\hline & 0.029609 & 0.030674 & 0.021113 \\
\hline \multirow{2}{*}{$V_{t-1}$} & - & $0.000101 *$ & $0.000060^{* \star *}$ \\
\hline & & 0.000037 & 0.000033 \\
\hline$\beta_{1}+\omega_{1}$ & 0.959 & 0.954 & 0.982 \\
\hline $\begin{array}{l}\text { Log } \\
\text { likelihood }\end{array}$ & 4871.041 & 4864.983 & 4980.853 \\
\hline
\end{tabular}

${ }^{a}$ The estimated coefficient ${ }^{b}$ Bollerslev and Wooldrige (1992) robust standard errors. ${ }^{*},{ }^{* *}$ and ${ }^{* * *}$ indicate significance at the levels of $1 \%, 5 \%$ and $10 \%$ respectively. 